\title{
Vírus Zika: Revisão para Clínicos
}

\author{
Zika Virus: A Review to Clinicians
}

Vitor Laerte PINTO JUNIOR $\rrbracket^{1,2}$, Kleber LUZ ${ }^{3}$, Ricardo PARREIRA², Paulo FERRINHO ${ }^{2}$

Acta Med Port 2015 Nov-Dec;28(6):760-765

\section{RESUMO}

O vírus Zika é um flavivírus filogeneticamente relacionado com o vírus dengue, vírus da febre-amarela e vírus do Nilo Ocidental. É considerado uma arbovirose emergente transmitida por mosquitos do género Aedes. A sua descoberta deu-se em 1947 na floresta Zika no Uganda, isolado em macaco Rhesus que servia de isco para estudo do vírus da febre-amarela. Foram detetados casos isolados em países de África e no final da década de 70 na Indonésia. A partir 2007 foram descritas epidemias na Micronésia e outras ilhas do Oceano Pacífico e, mais recentemente, no Brasil. Carateriza-se clinicamente como uma síndrome febril aguda 'tipo-dengue' com aparecimento precoce de exantema evanescente muitas vezes pruriginoso; ocasionalmente a doença tem sido associada à síndrome de Guillain-Barré. No entanto, até ao momento não foram relatadas mortes pela doença e suas complicações. O diagnóstico pode ser realizado por meio de técnica de reação em cadeia da polimerase ou por pesquisa de anticorpos IgG e IgM. A rápida disseminação do vírus e seu potencial epidémico são preocupantes especialmente em territórios com circulação de outras arboviroses pela dificuldade no diagnóstico diferencial e na sobrecarga dos serviços de saúde. As medidas de controlo são as mesmas recomendadas para a dengue e chikungunya, baseadas em educação em saúde e controlo do vetor.

Palavras-chave: Aedes; Arbovirus; Flavivírus; Infecções por Flaviviridae.

\section{ABSTRACT}

Zika virus is a flavivirus related to Dengue virus, yellow fever virus and West Nile virus. It is considered an emerging arbovirus transmitted by mosquitos of the genus Aedes. Its first description took place in 1947 in the Zika Forest in Uganda, isolated on Rhesus monkey used as bait to study the yellow fever virus. Sporadic cases have been detected in African countries and at the end of the 70's in Indonesia. In 2007, epidemics were described in Micronesia and other islands in the Pacific Ocean and more recently in Brazil. Clinical picture is characterized as a 'dengue-like' syndrome, with abrupt onset of fever and an early onset evanescent rash, often pruritic. Occasionally the disease has been associated with Guillain-Barré syndrome. Nevertheless, until now deaths and complications caused by the disease were not reported. The diagnosis can be performed by PCR or by IgG and IgM antibodies detection. The rapid spread of the virus and its epidemic potential are especially problematic in countries where there are the circulation of other arboviruses which imposes difficulties in the differential diagnosis and healthcare burden. Control measures are the same recommended for dengue and chikungunya which are based in health education and vector control.

Keywords: Aedes; Arboviruses; Flavivirus; Flaviviridae Infections.

\section{Etiologia}

$\mathrm{O}$ vírus Zika (ZIKV) pertence à família Flaviridae e ao género Flavivirus sendo, portanto, aparentado do ponto de vista evolutivo com outros arbovírus transmitidos por mosquitos, como o são o vírus dengue, vírus da febre-amarela (YFV) e vírus do Nilo Ocidental. Trata-se de um vírus com genoma de ácido ribonucléico (RNA) de cadeia simples de polaridade positiva. Apesar de não ser conhecida a estrutura do virião, por comparação aos demais flavivírus conhecidos, este deve ser limitado por um invólucro lipídico derivado do retículo endoplasmático das células onde estes vírus se replicam, invólucro esse que limita externamente uma nucleocápside com estrutura e simetria ainda não definidas, composta pela proteína $C$ e pelo genoma viral. $\mathrm{O}$ invólucro viral deverá conter as duas proteínas de superfície (designadas M e E), sendo que, adicionalmente, o genoma viral codifica uma série de outras proteínas, ditas não-estruturais que, ou possuem atividade enzimática
(NS3: helicase de RNA e protease e NS5: polimerase de RNA, dependente de RNA), ou desempenham funções regulatórias (controlo da replicação, transcrição, tradução e resposta imune) durante a replicação intracelular. ${ }^{1,2}$

O ZIKV foi isolado pela primeira vez em 1947 na floresta de Zika, no Uganda, a partir de uma amostra de soro de um macaco Rhesus que servia de sentinela para estudo vigilância da febre-amarela (FA). ${ }^{3}$ Após análise filogenética do genoma viral, percebeu-se que provavelmente o vírus surgiu nesta localidade em torno de 1920, e após duas fases de migração para o Oeste Africano deu início as duas linhagens africanas. Do Uganda, o vírus terá migrado na década de 1940 para a Ásia e aí originou a linhagem asiática, com surtos registados na Indonésia e a epidemia na Micronésia. ${ }^{14} \mathrm{~A}$ linhagem asiática também foi a responsável pelos casos de transmissão autótone deste vírus, recentemente ocorridos no Brasil. $^{5}$

1. Departamento de Epidemiologia e Vigilância em Saúde. Fiocruz Brasília. Brasília. Brasil.

2. Global Health and Tropical Medicine. Instituto de Higiene e Medicina Tropical. Universidade NOVA de Lisboa. Lisboa. Portugal.

3. Departamento de Doenças Infecciosas. Instituto de Medicina Tropical do Rio Grande do Norte. Universidade Federal do Rio Grande do Norte. Natal. Brasil.

$\square$ Autor correspondente: Vitor Laerte Pinto Junior. vitorlaerte@gmail.com

Recebido: 21 de Agosto de 2015 - Aceite: 03 de Dezembro de 2015 | Copyright @ Ordem dos Médicos 2015 


\section{Distribuição da doença}

Após o isolamento do vírus nos finais da década de 1940, foram detetados os primeiros casos de infeção por ZIKV em seres humanos no ano de 1952 na Uganda. ${ }^{6} \mathrm{Em}$ 1953 foram igualmente detetados casos na Nigéria ${ }^{7}$ e em 1956 mosquitos da espécie Aedes aegypti foram infetados laboratorialmente resultando em transmissão bem-sucedida do vírus em ratos em $60 \%$ dos casos. ${ }^{8} \mathrm{Na}$ década de 1960 , indivíduos com sorologia positiva para o ZIKV continuaram a ser identificados em inquéritos sorológicos levados a cabo na Nigéria e também em doentes com quadro febril durante epidemia de FA em 1970. ${ }^{9}$ Entre os anos de 1975 - 1977 foram encontradas evidências sorológicas e virológicas de infeção por ZIKV em Serra Leoa, Nigéria, Senegal, Gabão, Costa do Marfim e em países da África Central. ${ }^{10-15}$

A primeira evidência da circulação do vírus fora do continente africano deu-se entre os anos de 1977 e 1978, quando casos de doença febril aguda foram internados num hospital na Indonésia, sendo encontrados anticorpos contra o ZIKV no soro de 30 doentes. ${ }^{16} \mathrm{Na}$ última década foram documentadas duas epidemias causadas pelo ZIKV na Federação dos Estados da Micronésia (na ilha de Yap), constituindo-se o primeiro foco fora de África e da Ásia. ${ }^{17,18} \mathrm{~A}$ doença disseminou-se rapidamente pelas ilhas do Oceano Pacífico sendo detetados em outubro de 2013 os primeiros casos na Polinésia Francesa (PF), onde a situação evoluiu para uma epidemia com cerca de 19000 casos suspeitos e 284 casos confirmados de infeção pelo ZIKV. ${ }^{19}$

Em fevereiro de 2014, pela primeira vez nas Américas, casos da doença foram reportados na Ilha de Páscoa (território Chileno no Oceano Pacífico), provavelmente relacionado com o surto na Micronésia e na PF. ${ }^{20}$ Em 2015 foi confirmada a circulação do vírus no Nordeste do Brasil a partir de isolamento viral em casos suspeitos de dengue. ${ }^{5}$
Recentemente, o Ministério da Saúde do Brasil publicou uma nota a afirmar que casos da doença já haviam sido confirmados em mais oito estados do país, compreendendo as regiões norte, nordeste e sudeste. ${ }^{21}$ A Fig. 1 ilustra os países onde já se evidenciou a presença da infecção em inquéritos seroepidemiológicos e a transmissão autóctone da doença.

\section{Transmissão}

A transmissão do ZIKV é consequência da picada de mosquitos do género Aedes, tendo sido isolado em 1948 a partir de um macerado de mosquitos da espécie Ae. africanus colhidos na floresta de Zika. ${ }^{6}$ Estudos seroepidemiológicos levados a cabo com base em amostras de sangue coletadas em residentes dessa região do Uganda revelaram uma prevalência de anticorpos antiZIKV a rondar os $6 \% .{ }^{17}$ Adicionalmente, este vírus veio a ser repetidamente isolado de mosquitos colhidos quer em África, quer na Ásia, permitindo sugerir que espécies como Ae. africanus, Ae. aegypti e Ae. hensilli participem na sua manutenção enzoótica (em ambiente silvático). ${ }^{22-25}$

A competência vetorial para transmissão do ZIKV pelo Ae. aegyptie pelo Ae. albopictus impõe grande preocupação para a saúde pública. Estes artrópodes encontram-se amplamente distribuídos em zonas tropicais, subtropicais (Ae. aegypti) e temperadas (Ae. albopictus), abrangendo um enorme contingente de indivíduos suscetíveis. ${ }^{8,26}$

Menos frequentemente, a transmissão do ZIKV já foi descrita por via sexual, perinatal e por hemotransfusão. ${ }^{27-29}$ Apesar de possíveis, ainda não se tem a dimensão da importância epidemiológica destes mecanismos.

\section{Quadro clínico}

Ainda não há um completo conhecimento acerca das

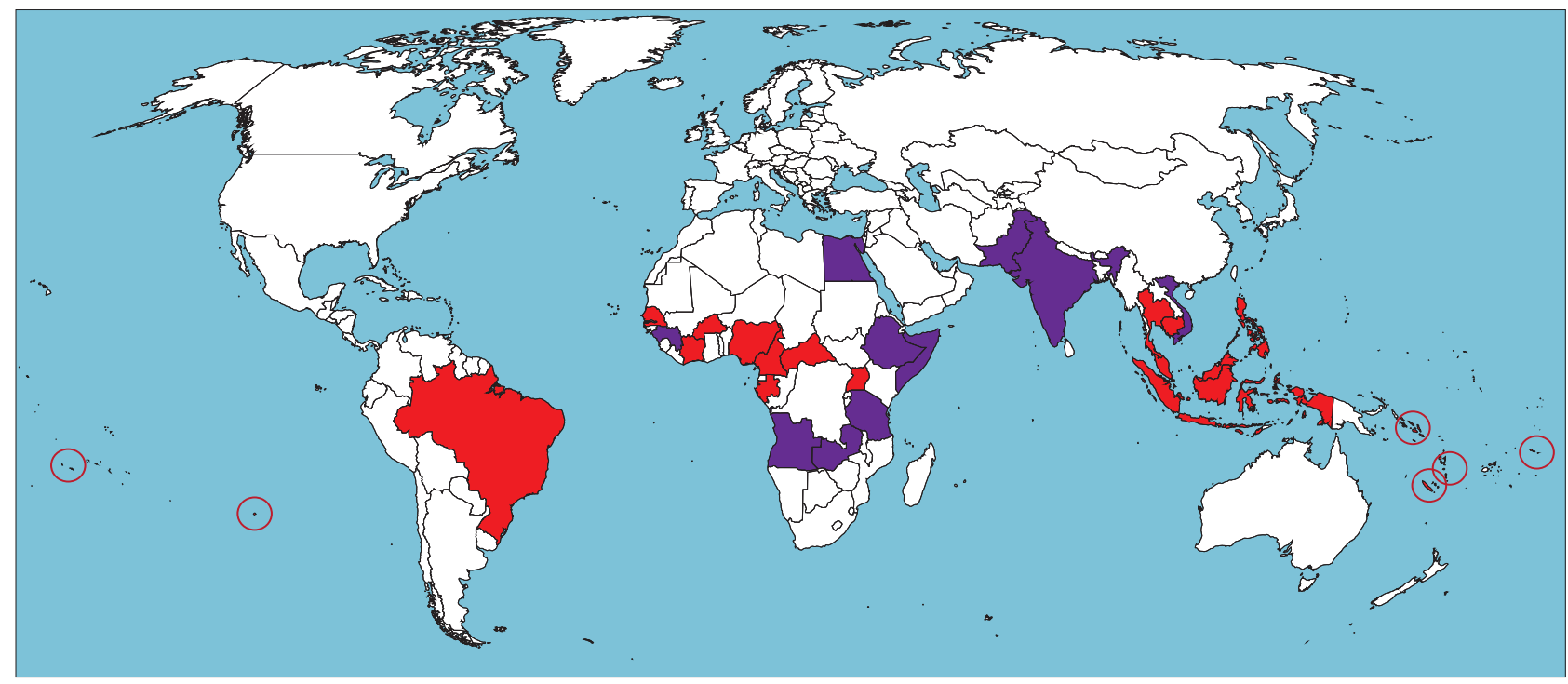

Países com casos autóctones Somente evidência serológica

Figura 1 - Países onde há evidência de transmissão autóctone ou resultados positivos em inquéritos seroepidemiológicos. Fonte: Centers for Disease Control, maio de 2015; adaptado por Acta Médica Portuguesa, dezembro de 2015. 
manifestações clínicas da infeção causada pelo ZIKV, as informações limitam-se a descrições de casos isolados ou série de casos em situações de epidemia. O período de incubação varia de três a 12 dias após a picada do mosquito infetado semelhantemente ao descrito para outras arboviroses. ${ }^{30,31}$ As manifestações clínicas da doença podem variar dependendo da localidade, sendo frequente uma síndrome 'tipo-dengue'. Infeções assintomáticas também são descritas a partir de resultados de inquéritos sorológicos. ${ }^{32-34}$

MacNamara ${ }^{7}$ descreveu os primeiros três casos humanos de infeção por ZIKV em 1954 na Nigéria, associados com icterícia. Todavia a localidade era endémica para malária e FAe, portanto, não foi possível diferenciar as manifestações da doença por ZIKV das outras doenças. Posteriormente, Bearcroft ${ }^{35}$ induziu a infeção num voluntário saudável por meio de exposição a fêmeas de Ae. aegypti infetadas; o paciente evoluiu com um quadro febril inespecífico e autolimitado sem exantema, três dias após a inoculação. De facto, este indivíduo infetado experimentalmente não parece ter desenvolvido virémia suficientemente intensa para permitir a transmissão do ZIKV aos Ae. Aegypti que sobre ele se alimentaram.

As descrições de casos da doença em África nos anos seguintes caraterizaram a doença por ZIKV como um episódio febril de início agudo, acompanhado de cefaleia discreta, surgimento de exantema maculopapular pruriginoso, no segundo dia, acometendo a face, o tronco, os membros, as palmas das mãos e as plantas dos pés

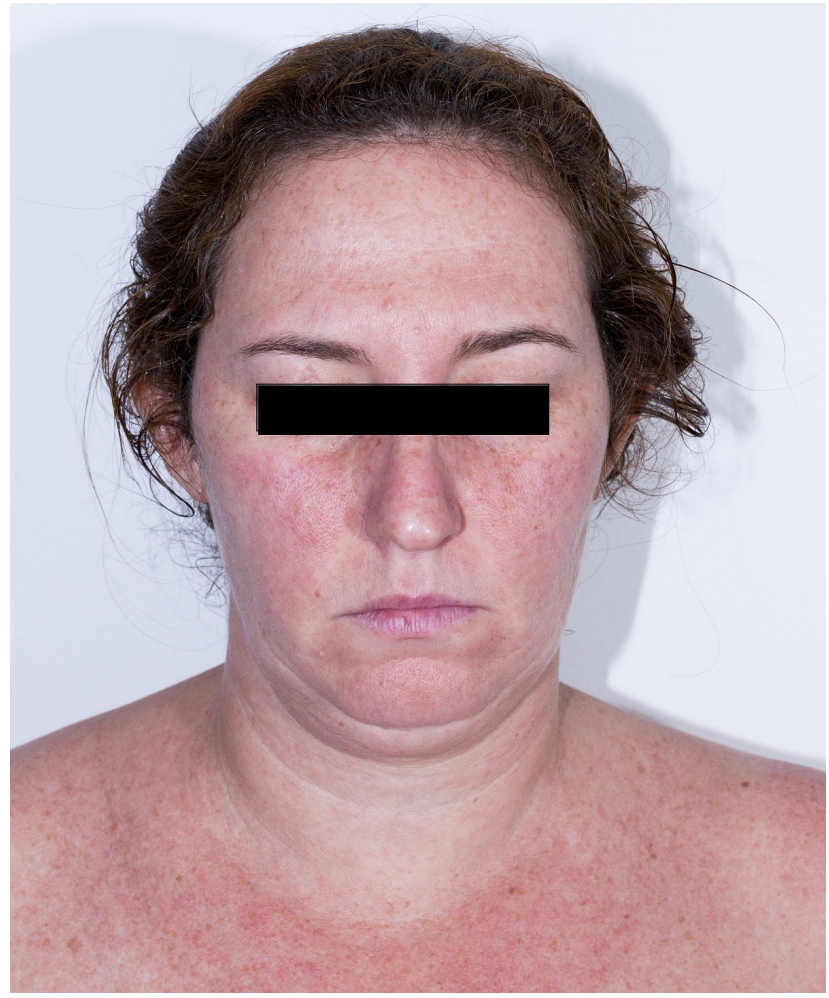

Figura 2 - Exantema causado pela infecção pelo vírus Zika em mulher de 39 anos residente na cidade do Rio de Janeiro, Brasil. O diagnóstico foi confirmado por critério clínico-epidemiológico e serologia negativa para o vírus dengue.
(Fig. 2). A febre cede um dia ou dois após o aparecimento do exantema, que pode persistir por mais dois a 14 dias (duração média de seis dias). ${ }^{11,36}$

Habitualmente a febre é baixa, mas em alguns casos relatados no Brasil foi elevada, chegando a $39^{\circ} \mathrm{C} .{ }^{5}$ São relatadas mialgia, dores articulares e dor lombar discreta, mas diferentemente dos casos de chikungunya, as dores são menos intensas e acometem mais as mãos, joelhos e tornozelos. Geralmente o seu desaparecimento ocorre cerca de uma semana, com duração média de três a cinco dias..$^{18,19,33} \mathrm{~A}$ conjuntivite tem sido frequentemente relatada e, carateristicamente, não apresenta secreção purulenta (Fig. 3). ${ }^{37}$ Podem ocorrer outras manifestações inespecíficas como anorexia, náuseas, vómitos, vertigem e dor retro-orbital. ${ }^{16}$

Pode considerar-se que a infeção pelo ZIKV tem evolução benigna, mas assim como na epidemia que ocorreu na PA, no Brasil têm-se registado muitos casos de Síndrome de Guillain-Barré (SGB) que surgiram poucos dias após o desenvolvimento do quadro clínico da infeção. O mecanismo desencadeador desta condição ainda não é conhecido, sendo provável um fenómeno de autoimunidade como observado noutras infeções. Até ao momento não houve registo de óbito nos doentes que desenvolveram a SGB, embora alguns casos tenham necessitado de tratamento em unidades de terapia intensiva. Apesar disso, a associação entre a infeção por ZIKV e a SGB ainda carece de comprovação por meio de estudos analíticos. ${ }^{20,38}$

Até hoje, a co-infecção dengue e ZIKV não demonstrou efeito sinergético em relação à gravidade ou as manifestações clínicas das duas doenças. Dois casos de co-infeção foram relatados na Nova Caledónia (Oceânia), com boa evolução sem a necessidade de hospitalização. ${ }^{39}$

Informações acerca das alterações hematológicas e bioquímicas na doença pelo ZIKV são escassas na literatura e também conflituantes. Em alguns relatos de casos são descritos aumento da desidrogenase lática e da proteína $\mathrm{C}$ reativa. Pode haver leucopenia e trombocitopenia discretas. ${ }^{40}$

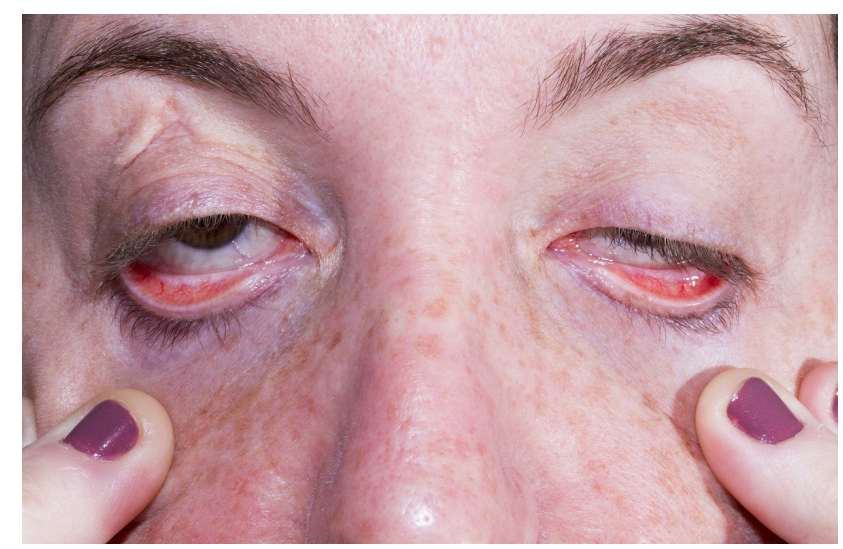

Figura 3 - Congestão conjuntival causada pela infecção pelo vírus Zika em mulher de 39 anos residente na cidade do Rio de Janeiro, Brasil. O diagnóstico foi confirmado por critério clínico-epidemiológico e serologia negativa para o vírus dengue. 
Tabela 1 - Manifestações clínicas mais frequentes febres provocadas por vírus dengue, vírus chikungunya e vírus Zika.

\begin{tabular}{|c|c|c|c|}
\hline Sintoma & Dengue & Chikungunya & Zika \\
\hline Febre (intensidade) & +++ & ++ & + \\
\hline Mialgia & +++ & ++ & + \\
\hline Exantema & + & ++ & +++ \\
\hline Artralgia & $+/-$ & +++ & + \\
\hline Cefaleia & +++ & + & + \\
\hline Conjuntivite & - & ++ & +++ \\
\hline Discrasia & ++ & $+/-$ & - \\
\hline Choque & +++ & $+/-$ & - \\
\hline Plaquetopenia & +++ & $+/-$ & $+/-$ \\
\hline Neutropenia & ++ & + & SI \\
\hline Linfopenia & ++ & +++ & SI \\
\hline
\end{tabular}

Adaptado do Manual de Manejo Clínico do Chikungunya, Ministério da Saúde, Brasil, 2014.

O diagnóstico diferencial faz-se principalmente com dengue e chikungunya. Na Tabela 1 são apresentadas as diferenças entre as manifestações clínicas das três doenças. ${ }^{30}$ As doenças exantemáticas causadas por vírus como o Human parvovirus B19, infeção pelo vírus EpsteinBarr, sarampo e rubéola entre outras devem também ser investigadas pela sua alta capacidade de transmissão na comunidade. ${ }^{41} \mathrm{~A}$ infeção por ZIKV também deve ser considerada em casos de febre pós-viagem em indivíduos que retornam de países de clima tropical. ${ }^{42-44}$

Não se conhecem casos de reinfeções pelo ZIKV, pensando-se que uma infeção dá imunidade permanente.

\section{Diagnóstico laboratorial}

Em virtude da não existência, até ao presente, de testes comerciais que permitam o diagnóstico sorológico de infeções por ZIKV, o diagnóstico da infeção aguda por este vírus pode ser realizado por meio de RT-PCR (amplificação por reação em cadeia da polimerase, antecedida de transcrição reversa), a partir de RNA diretamente extraído do soro do doente, preferencialmente colhido até o sexto dia de doença. No entanto, num caso da epidemia da ilha Yap, o vírus foi identificado (através da amplificação de genoma viral) ao $11^{\circ}$ dia após o início dos sintomas. ${ }^{18,45}$ $O$ vírus também pode ser detetado por meio de técnicas moleculares aplicadas noutros fluidos corporais como a saliva e a urina. ${ }^{46,47}$

Anticorpos IgM podem ser encontrados a partir do terceiro dia de doença e anticorpos IgG devem ser pesquisados no soro agudo e convalescente. 17, $48 \mathrm{Um}$ problema em relação aos testes sorológicos é a possibilidade de reação cruzada como resultado de infeções prévias por outros flavivírus. ${ }^{17,18,49}$ A ocorrência de epidemias de ZIKV em territórios onde previamente haja circulação do vírus dengue pode representar desafio diagnóstico. Mesmo a realização de um teste de neutralização por redução de placa (PRNT), também utilizado na epidemia na ilha Yap, teve dificuldade em diferenciar casos prováveis de infeção por ZIKV em doentes com anticorpos contra dengue adquiridos previamente, apesar de que os títulos anti-ZIKV apresentados sempre foram maiores que os heterólogos (não-ZIKV). ${ }^{18}$

Ainda assim, vários têm sido os estudos que reportam avaliações quer qualitativas, quer quantitativas, da presença de anticorpos anti-ZIKV em amostras biológicas, sendo que algumas das técnicas empregues não são técnicas padronizadas, sendo utilizadas em contextos laboratoriais específicos (técnicas in-house).

Apesar da existência de testes diagnósticos, seu uso ainda é bastante restrito por não haver kits comerciais disponíveis no mercado. Portanto, o diagnóstico é limitado às instituições governamentais ligadas à vigilância em saúde, ou instituições de ensino e investigação. A deteção de genomas virais por RT-PCR é o método mais sensível e específico para permitir um diagnóstico de infeções a ZIKV, no entanto esses métodos não são, por enquanto, fail-safe. Ao contrário do que acontece para outros vírus, a circulação restrita deste vírus tem limitado o conhecimento sobre a sua real diversidade genética, pelo que há uma probabilidade diferente de zero que os primers utilizados nas amplificações de genoma de ZIKV possam não permitir as amplificações pretendidas (falsos negativos de amplificação). Este caso deverá ser avaliado daqui em diante.

\section{Tratamento}

Não existem vacinas nem medicamentos antivirais específicos, sendo o tratamento sintomático. A utilização 
de analgésicos e antipiréticos deve ser criteriosa para se evitar a indução de efeitos adversos, como hepatopatia, alergias e nefropatia. $\mathrm{O}$ uso de aspirina (salicilatos) deve ser desencorajado para evitar a indução de fenómenos hemorrágicos em doentes com dengue diagnosticados erroneamente como infeções pelo ZIKV em virtude do diagnóstico clínico não ser conclusivo e mesmo a análise serológica apresentar possibilidade de falha.

$O$ intenso prurido que acompanha o exantema tem sido relatado pelos doentes como um sério desconforto. A abordagem terapêutica para aliviar os sintomas pode iniciarse com a orientação de se evitarem banhos quentes, uso excessivo de sabão e na correta hidratação da pele. Caso não haja resposta satisfatória recomendam-se banhos frios e o uso de loções refrescantes contendo calamina ou mentol. A patogenia das manifestações cutâneas ainda é obscura, portanto o uso de anti-histamínicos mais antigos pode beneficiar o doente mais pela sedação que causam do que pela sua atuação na causa do prurido..$^{50,51}$ Os corticosteroides não devem ser utilizados por se desconhecer a sua eficácia na regressão deste sintoma.

A SGB deve ser abordada de maneira convencional. $O$ diagnóstico é feito pela constatação de fraqueza progressiva em dois ou mais membros, arreflexia e evolução no máximo em quatro semanas. A análise do líquor pode revelar aumento de proteínas e baixa celularidade (dissociação albumino-citológica). Os doentes suspeitos devem ser monitorizados em unidades de cuidados intensivos pelo risco de evolução de paralisia da musculatura respiratória. As opções terapêuticas para a SGB incluem plasmaferese ou imunoglobulina hiperimune intravenosa: ambas são dispendiosas, mas diminuem o tempo até a recuperação. ${ }^{52}$

\section{Medidas de controlo}

O Ae. aegypti é um mosquito altamente sinantrópico, que tira partido dos ambientes peridomésticos e que, inclusive, pode fazer as suas refeições sanguíneas no interior das habitações humanas. Tendo em conta que é um dos vetores do ZIKV e dado que medidas de controlo vetorial baseadas na utilização de inseticidas podem ser complicadas por (i) restrições financeiras, (ii) questões logísticas, (iii) regulamentação apertada no uso de inseticidas e/ou (iv) disseminação de resistências na população vetorial, a eliminação dos criadouros de larvas assume um papel importante no controlo deste vetor. As medidas de proteção individual também devem ser encorajadas, como uso de repelentes e instalação de telas em janelas e portas. A vigilância em saúde deve priorizar a deteção e a investigação de casos suspeitos com o objetivo de interromper a transmissão em áreas mais problemáticas. Os indivíduos com doença ativa ou que a tiveram recentemente não podem doar sangue. ${ }^{53}$

Apesar de até ao momento não terem ocorrido óbitos por ZIKV, os profissionais de saúde devem estar cientes e treinados para diferenciar a doença pelo ZIKV de outras doenças que circulam simultaneamente, nomeadamente a dengue. ${ }^{39}$

Nas áreas indemnes deve-se priorizar a atenção de viajantes que retornam de áreas com transmissão de ZIKV. O reconhecimento precoce pode contribuir para tomada de medidas de forma que a doença não se dissemine, tendo em vista a expansão do Ae. albopictus em zonas temperadas. ${ }^{43}$

\section{CONCLUSÃO}

As epidemias causadas pelo ZIKV durante a última década resultaram numa notável disseminação da Ásia e do Oceano Pacífico para as Américas. Ainda não se sabe se este flavivírus se irá estabelecer nestes novos territórios, sendo necessários mais estudos sobre a sua dinâmica de transmissão.

A sua ocorrência em áreas onde já se observa a transmissão de outros flavivírus, como os diferentes serotipos dos vírus da dengue, traz a possibilidade de aumento da mortalidade por dificuldades no diagnóstico diferencial e também pela indisponibilidade de kits diagnósticos comerciais. Apesar do caráter aparentemente benigno da doença, complicações potencialmente fatais como a SGB despontam como nova problemática a ser considerada na atenção aos indivíduos acometidos pela doença em áreas de transmissão ativa.

As medidas de controlo vetorial devem ser intensificadas, assim como as ações de assistência. Em áreas indemnes e onde haja a circulação de mosquitos do género Aedes, deve-se ter cuidado com os viajantes oriundos nomeadamente de áreas tropicais.

\section{PROTECÇÃO DE PESSOAS E ANIMAIS}

Os autores declaram que os procedimentos seguidos estavam de acordo com os regulamentos estabelecidos pelos responsáveis da Comissão de Investigação Clínica e Ética e de acordo com a Declaração de Helsínquia da Associação Médica Mundial.

\section{CONFIDENCIALIDADE DOS DADOS}

Os autores declaram ter seguido os protocolos do seu centro de trabalho acerca da publicação de dados.

\section{CONFLITOS DE INTERESSE}

Os autores declaram não terem qualquer conflito de interesse relativamente ao presente artigo.

\section{FONTES DE FINANCIAMENTO}

O primeiro autor recebeu apoio por meio do programa de pós-doutoramento no exterior da CAPES/MEC processo no. 99999.007391/2014-05. 


\section{REFERÊNCIAS}

1. Haddow AD, Schuh AJ, Yasuda CY, Kasper MR, Heang V, Huy R, et al. Genetic characterization of Zika virus strains: geographic expansion of the Asian lineage. PLoS Negl Trop Dis. 2012;6:e1477.

2. Kuno G, Chang GJ. Full-length sequencing and genomic characterization of Bagaza, Kedougou, and Zika viruses. Arch Virol. 2007;152:687-96.

3. Dick GW, Kitchen SF, Haddow AJ. Zika virus. I. Isolations and serological specificity. Trans R Soc Trop Med Hyg. 1952;46:509-20.

4. Faye O, Freire CC, lamarino A, Faye O, de Oliveira JV, Diallo M, et al. Molecular evolution of Zika virus during its emergence in the 20(th) century. PLoS Negl Trop Dis. 2014;8:e2636.

5. Zanluca C, Melo VC, Mosimann AL, Santos GI, Santos CN, Luz K. First report of autochthonous transmission of Zika virus in Brazil. Mem Inst Oswaldo Cruz. 2015;110:569-72.

6. Dick GW. Epidemiological notes on some viruses isolated in Uganda; Yellow fever, Rift Valley fever, Bwamba fever, West Nile, Mengo, Semliki forest, Bunyamwera, Ntaya, Uganda S and Zika viruses. Trans R Soc Trop Med Hyg. 1953;47:13-48.

7. Macnamara FN. Zika virus: a report on three cases of human infection during an epidemic of jaundice in Nigeria. Trans $\mathrm{R}$ Soc Trop Med Hyg. 1954;48:139-45

8. Boorman JP, Porterfield JS. A simple technique for infection of mosquitoes with viruses; transmission of Zika virus. Trans R Soc Trop Med Hyg. 1956;50:238-42.

9. Monath TP, Wilson DC, Casals J. The 1970 yellow fever epidemic in Okwoga District, Benue Plateau State, Nigeria. 3. Serological responses in persons with and without pre-existing heterologous group B immunity. Bull World Health Organ. 1973;49:235-44.

10. Robin Y, Mouchet J. Serological and entomological study on yellow fever in Sierra Leone. Bull Soc Pathol Exot Filiales. 1975;68:249-58.

11. Fagbami A. Epidemiological investigations on arbovirus infections at Igbo-Ora, Nigeria. Trop Geogr Med. 1977;29:187-91.

12. Jan C, Languillat G, Renaudet J, Robin Y. A serological survey of arboviruses in Gabon. Bull Soc Pathol Exot Filiales. 1978;71:140-6.

13. Renaudet J, Jan C, Ridet J, Adam C, Robin Y. A serological survey of arboviruses in the human population of Senegal. Bull Soc Pathol Exot Filiales. 1978;71:131-40

14. Chippaux A, Chippaux-Hyppolite C, Monteny-Vandervorst N, Souloumiac-Deprez D. Several yellow fever cases in an endemic area in Ivory Coast: serological and epidemiological evidence. Med Trop. 1981;41:53-61.

15. Saluzzo JF, Gonzalez JP, Hervé JP, Georges AJ. Serological survey for the prevalence of certain arboviruses in the human population of the south-east area of Central African Republic. Bull Soc Pathol Exot Filiales. 1981;74:490-9.

16. Olson JG, Ksiazek TG, Suhandiman, Triwibowo. Zika virus, a cause of fever in Central Java, Indonesia. Trans R Soc Trop Med Hyg. 1981;75:389-93.

17. Lanciotti RS, Kosoy OL, Laven JJ, Velez JO, Lambert AJ, Johnson AJ, et al. Genetic and serologic properties of Zika virus associated with an epidemic, Yap State, Micronesia, 2007. Emerg Infect Dis. 2008;14:12329.

18. Duffy MR, Chen TH, Hancock WT, Powers AM, Kool JL, Lanciotti RS, et al. Zika virus outbreak on Yap Island, Federated States of Micronesia. N Engl J Med. 2009;360:2536-43.

19. Cao-Lormeau VM, Roche C, Teissier A, Robin E, Berry AL, Mallet HP, et al. Zika virus, French polynesia, South pacific, 2013. Emerg Infect Dis. 2014;20:1085-6.

20. Musso D, Nilles EJ, Cao-Lormeau VM. Rapid spread of emerging Zika virus in the Pacific area. Clin Microbiol Infect. 2014;20:0595-6.

21. Promed-mail [homepage da internet]. Zika vírus - brasil (11) (vários estados), casos confirmados. [consultado 2015 Jul 20]. Disponível em: http://www.promedmail.org/direct.php?id=20150612.3431199.

22. Marchette NJ, Garcia R, Rudnick A. Isolation of Zika virus from Aedes aegypti mosquitoes in Malaysia. Am J Trop Med Hyg. 1969;18:411-5.

23. Weinbren MP, Williams MC. Zika virus: further isolations in the Zika area, and some studies on the strains isolated. Trans R Soc Trop Med Hyg. 1958;52:263-8.

24. Haddow AJ, Williams MC, Woodall JP, Simpson DI, Goma LK. Twelve isolations of zika virus from aedes (stegomyia) africanus (theobald) taken in and above a Uganda forest. Bull World Health Organ. 1964;31:57-69.

25. Ledermann JP, Guillaumot L, Yug L, Tided M, Machieng P, Pretrick M, et al. Aedes hensilli as a potential vector of Chikungunya and Zika viruses. PLoS Negl Trop Dis. 2014;8:e3188.

26. Grard G, Caron M, Mombo IM, Nkoghe D, Mboui Ondo S, Jiolle D, et al. Zika virus in Gabon (Central Africa)--2007: a new threat from Aedes albopictus? PLoS Negl Trop Dis. 2014;8:e2681.

27. Besnard M, Lastere S, Teissier A, Cao-Lormeau V, Musso D. Evidence of perinatal transmission of Zika virus, French Polynesia, December 2013 and February 2014. Euro Surveill. 2014;19.

28. Musso D, Roche C, Robin E, Nhan T, Teissier A, Cao-Lormeau VM. Potential sexual transmission of Zika virus. Emerg Infect Dis. 2015;21:359-61.

29. Musso D, Nhan T, Robin E, Roche C, Bierlaire D, Zisou K, et al. Potential for Zika virus transmission through blood transfusion demonstrated during an outbreak in French Polynesia, November 2013 to February 2014. Euro Surveill. 2014;19.

30. Ioos S, Mallet HP, Leparc Goffart I, Gauthier V, Cardoso T, Herida M. Current Zika virus epidemiology and recent epidemics. Med Mal Infect. 2014;44:302-7.

31. Rudolph KE, Lessler J, Moloney RM, Kmush B, Cummings DA Incubation periods of mosquito-borne viral infections: a systematic review. Am J Trop Med Hyg. 2014;90:882-91

32. Geser A, Henderson BE, Christensen S. A multipurpose serological survey in Kenya. 2. Results of arbovirus serological tests. Bull World Health Organ. 1970;43:539-52.

33. Heang V, Yasuda CY, Sovann L, Haddow AD, Travassos da Rosa AP, Tesh RB, et al. Zika virus infection, Cambodia, 2010. Emerg Infect Dis. 2012;18:349-51.

34. Fagbami AH. Zika virus infections in Nigeria: virological and seroepidemiological investigations in Oyo State. J Hyg. 1979;83:213-9.

35. Bearcroft WG. Zika virus infection experimentally induced in a human volunteer. Trans R Soc Trop Med Hyg. 1956;50:442-8.

36. Simpson DI. Zika virus infection in man. Trans R Soc Trop Med Hyg 1964;58:335-8

37. Promed-mail [homepage na internet]. Zika virus outbreak - micronesia (yap) (02): confirmed; [consultado 2015 Jul 19]. Disponível em: http:// www.promedmail.org/direct.php?id=15686.

38. Oehler E, Watrin L, Larre P, Leparc-Goffart I, Lastere S, Valour F, et al. Zika virus infection complicated by Guillain-Barre syndrome--case report, French Polynesia, December 2013. Euro Surveill. 2014;19.

39. Dupont-Rouzeyrol $M$, O'Connor $O$, Calvez $E$, Daurès $M$, John $M$, Grangeon JP, et al. Co-infection with Zika and dengue viruses in 2 patients, New Caledonia, 2014. Emerg Infect Dis. 2015;21:381-2.

40. Zammarchi L, Stella G, Mantella A, Bartolozzi D, Tappe D, Günther $S$, et al. Zika virus infections imported to Italy: clinical, immunological and virological findings, and public health implications. J Clin Virol. 2015:63:32-5.

41. Keighley CL, Saunderson RB, Kok J, Dwyer DE. Viral exanthems. Curr Opin Infect Dis. 2015;28:139-50.

42. Zammarchi L, Tappe D, Fortuna C, Remoli ME, Günther S, Venturi G, et al. Zika virus infection in a traveller returning to Europe from Brazil, March 2015. Euro Surveill. 2015;20.

43. Summers DJ, Acosta RW, Acosta AM. Zika Virus in an American Recreational Traveler. J Travel Med. 2015;22:338-40.

44. Fonseca K, Meatherall B, Zarra D, Drebot M, MacDonald J, Pabbaraju $\mathrm{K}$, et al. First case of Zika virus infection in a returning Canadian traveler. Am J Trop Med Hyg. 2014;91:1035-8.

45. Faye O, Dupressoir A, Weidmann M, Ndiaye M, Alpha Sall A. One-step RT-PCR for detection of Zika virus. J Clin Virol. 2008;43:96-101.

46. Musso D, Roche C, Nhan TX, Robin E, Teissier A, Cao-Lormeau VM. Detection of Zika virus in saliva. J Clin Virol. 2015;68:53-5.

47. Gourinat AC, O'Connor O, Calvez E, Goarant C, Dupont-Rouzeyrol M. Detection of Zika virus in urine. Emerg Infect Dis. 2015;21:84-6.

48. European Center of Disease Control and Prevention [homepage na internet]. Rapid Risk Assessment. Zika virus infection outbreak, Brazil and the Pacific region; [consultado 2015 Jul 19]. Disponível em: http:// ecdc.europa.eu/en/publications/Publications/rapid-risk-assessmentZika\%20virus-south-america-Brazil-2015.pdf2015.

49. Mansfield KL, Horton DL, Johnson N, Barrett AD, Smith DJ, Galbraith SE, et al. Flavivirus-induced antibody cross-reactivity. J Gen Virol. 2011;92:2821-9.

50. Nelwan EJ, Pohan HT. Dengue convalescent rash in adult indonesian patients. Acta Med Indones. 2014;46:339-40.

51. Simmons CP, Farrar JJ, Nguyen V, Wills B. Dengue. N Engl J Med. 2012;366:1423-32

52. Ansar V, Valadi N. Guillain-Barré syndrome. Prim Care. 2015:42:189-93

53. Hayes EB. Zika virus outside Africa. Emerg Infect Dis. 2009;15:1347-50. 


\section{Vírus Zika: Revisão para Clínicos}

Acta Med Port 2015:28:760-765

Publicado pela Acta Médica Portuguesa, a Revista Científica da Ordem dos Médicos

Av. Almirante Gago Coutinho, 151

1749-084 Lisboa, Portugal.

Tel: +351218428 215

E-mail: submissao@actamedicaportuguesa.com

www.actamedicaportuguesa.com

ISSN:0870-399X | e-ISSN: 1646-0758

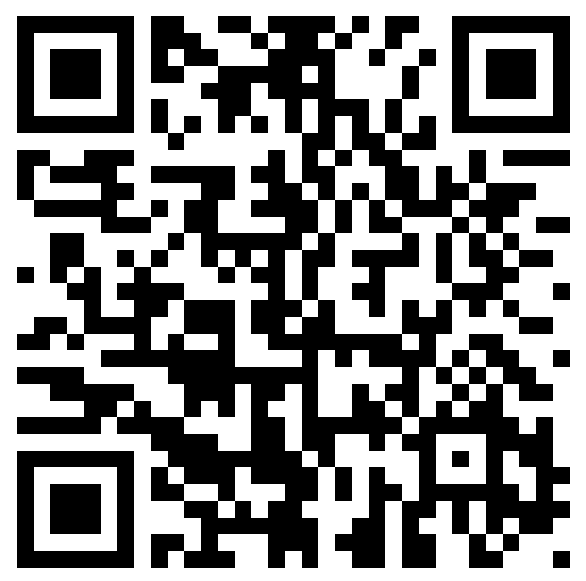

